\title{
The role of Asprosin in patients with dilated cardiomyopathy
}

\author{
Ming-Shien Wen ${ }^{1 *}$, Chao-Yung Wang ${ }^{1,2^{*}}$ (D), Jih-Kai Yeh ${ }^{1}$, Chun-Chi Chen ${ }^{1}$, Ming-Lung Tsai ${ }^{1}$, Ming-Yun Ho ${ }^{1}$, \\ Kuo-Chun Hung ${ }^{1}$ and I-Chang Hsieh ${ }^{1}$
}

\begin{abstract}
Background: Asprosin is a novel fasting glucogenic adipokine discovered in 2016. Asprosin induces rapid glucose releases from the liver. However, its molecular mechanisms and function are still unclear. Adaptation of energy substrates from fatty acid to glucose is recently considered a novel therapeutic target in heart failure treatment. We hypothesized that the asprosin is able to modulate cardiac mitochondrial functions and has important prognostic implications in dilated cardiomyopathy (DCM) patients.

Methods: We prospectively enrolled 50 patients ( $86 \%$ male, mean age $55 \pm 13$ years) with DCM and followed their 5-year major adverse cardiovascular events from 2012 to 2017. Comparing with healthy individuals, DCM patients had higher asprosin levels (191.2 versus $79.7 \mathrm{ng} / \mathrm{mL}, P<0.01$ ).

Results: During the 5-year follow-up in the study cohort, 16 (32.0\%) patients experienced adverse cardiovascular events. Patients with lower asprosin levels $(<210 \mathrm{ng} / \mathrm{mL})$ were associated with increased risks of adverse clinical outcomes with a hazard ratio of $7.94(95 \% \mathrm{Cl} 1.88-33.50, P=0.005)$ when compared patients with higher asprosin levels ( $\geq 210 \mathrm{ng} / \mathrm{mL}$ ). Using cardiomyoblasts as a cellular model, we showed that asprosin prevented hypoxiainduced cell death and enhanced mitochondrial respiration and proton leak under hypoxia.

Conclusions: In patients with DCM, elevated plasma asprosin levels are associated with less adverse cardiovascular events in five years. The underlying protective mechanisms of asprosin may be linked to its functions relating to enhanced mitochondrial respiration under hypoxia.
\end{abstract}

Keywords: Asprosin, Dilated cardiomyopathy, Heart failure, Hypoxia, Obesity

\section{Introduction}

Heart failure (HF) is a growing global public health problem, particularly in the elderly population, affecting more than 26 million patients worldwide [1]. The health care expenditure attributed to heart failure in Europe and North America reaches around 1-2\% recently $[2,3]$.

Despite encouraging advances in heart failure medications and device therapy, mortality and readmission rates in HF patients are still around $15-30 \%$ over the past 15

\footnotetext{
* Correspondence: wenms123@gmail.com; cwang@ocean.ag

'Department of Cardiology, Chang Gung Memorial Hospital, and Chang

Gung University College of Medicine, 5 Fu-Hsing Street, Taoyuan 333, Taiwan

Full list of author information is available at the end of the article
}

years [4]. The development of new therapeutics to avoid HF readmission are the current major target of many studies. Therefore, it is imperative to explore a novel mechanism to prevent heart failure or to develop an efficient target for improving heart function [5].

Most current HF treatments emphasize reducing myocardial workload and energy consumption, such as alleviating preload or afterload, reducing heart rate, and modulating neurohormonal activation [6]. Over the last decades, studies have focused on cardiac energy metabolism. This leads to the discovery of several novel compounds to balance the energy expenditure mismatching of HF patients $[7,8]$. Previous studies have found that there are

(c) The Author(s). 2020 Open Access This article is licensed under a Creative Commons Attribution 4.0 International License, which permits use, sharing, adaptation, distribution and reproduction in any medium or format, as long as you give appropriate credit to the original author(s) and the source, provide a link to the Creative Commons licence, and indicate if changes were made. The images or other third party material in this article are included in the article's Creative Commons licence, unless indicated otherwise in a credit line to the material. If material is not included in the article's Creative Commons licence and your intended use is not permitted by statutory regulation or exceeds the permitted use, you will need to obtain permission directly from the copyright holder. To view a copy of this licence, visit http://creativecommons.org/licenses/by/4.0/ The Creative Commons Public Domain Dedication waiver (http://creativecommons.org/publicdomain/zero/1.0/) applies to the data made available in this article, unless otherwise stated in a credit line to the data. 
significantly decreased mitochondria energy generation and transfer capacity in the cardiomyocytes of HF patients [911]. The bioenergetics impairment in the failing heart is reflected by underlying mitochondrial abnormalities, such as impaired electron transport chain activity [12], increased formation of reactive oxygen species [13], shifted metabolic substrate utilization [14, 15], and altered ion homeostasis [16].

Asprosin is a novel fasting-induced glucogenic adipokine [17]. It is a C-terminal cleavage product of profibrillin. Asprosin mainly secrets from white adipose tissues into circulation [18]. Asprosin stimulates glucose releases from hepatic cells through activation of the $G$ protein-cyclic AMP-protein kinase A pathway. The secretion of asprosin displays a circadian oscillation and is influenced by the dietary supplements [19]. Overnight fasting results in increases in asprosin concentrations while feeding decreases asprosin concentrations. Furthermore, elevated plasma asprosin concentrations are found to be associated with serum insulin levels and insulin resistance in humans and mice [20]. In opposition, patients with truncating mutation of FBN1 coding profibrillin have lower plasma asprosin and insulin levels than unaffected people [21]. Moreover, higher asprosin concentrations before bariatric surgery were associated with the weight reduction magnitude at 6 months after surgery [22].

Given the switching of energy source from fatty acid toward glycolytic pathways in the mitochondria of failing hearts, rapid and precise regulation of plasma glucose by glucogenic adipokines might be an important mechanism to fulfill the energy requirement of cardiomyocytes, especially in response to hemodynamic stress. Based on this energy adaptation mechanism, we hypothesized that asprosin can modulate the clinical outcomes in patients with dilated cardiomyopathy (DCM) and affect mitochondrial functions in cardiomyocytes.

\section{Methods}

\section{Study design and population}

We prospectively enrolled patients presented with heart failure and have a diagnosis of dilated cardiomyopathy at the Chang Gung Memorial Hospital [23]. The diagnostic criteria of dilated cardiomyopathy included (1) typical heart failure symptoms, such as shortness of breath, pulmonary or peripheral edema and elevated jugular venous pressure; (2) transthoracic echocardiography evaluation showed left ventricular or biventricular systolic dysfunction and dilatation by the European Society of Cardiology guideline [24]. The left ventricular ejection fraction was below $35 \%$, which was calculated using the modified Simpson's biplane method with apical four-chamber view; (3) the absence of hypertension, valvular heart disease, diabetes mellitus, heavy alcohol consumption, cardiotoxicity drug exposure and systemic inflammatory diseases in a series of diagnostic workup, (4) no coronary artery abnormalities confirmed by cardiac catheterization. The plasma brain natriuretic peptide (BNP) was also measured. Health participants without a previous history of heart diseases with normal left ventricular ejection fraction by echocardiography and normal exercise treadmill tests served as the normal control subjects.

The pre-specified composite endpoints include allcause mortality, heart failure re-hospitalization, cardiac transplantation, stroke, new-onset atrial fibrillation, ventricular tachycardia, and implantable cardioverterdefibrillator. Heart failure re-hospitalization was defined as hospital readmission with heart failure treatment, which requiring diuretics, vasodilators, or inotropic agents. When patients had multiple events, the time to the first event was counted as the censored outcome. All patients provided written informed consent. These studies complied with the declaration of Helsinki, and the study protocol was approved by the institutional review board of the Chang Gung Memorial Hospital.

\section{Serum samples and measurement of asprosin}

Venous blood was drawn from patients and normal subjects after $8 \mathrm{~h}$ of fasting and plasmas were stored at $80^{\circ} \mathrm{C}$ until analysis. For the designing and characterization of the endogenous asprosin sandwich ELISA, a mouse monoclonal anti-asprosin antibody against asprosin amino acids (human profibrillin amino acids 2832-2871) was used as the capture antibody and a goat anti-asprosin polyclonal antibody against asprosin amino acids 6-19 (human profibrillin amino acids 2737-2750) by Abnova was used as the detection antibody. An anti-goat secondary antibody linked to HRP was used to generate a signal. Serial dilution assay and spike/recovery test against human asprosin protein as positive control were used to establish the accuracy of the ELISA [22].

\section{Cell culture and protein analysis}

The H9c2 cell line was from American Tissue Type Collection (catalog \# CRL-1446) and cultured in DMEM medium supplemented with $1.5 \mathrm{~g} / \mathrm{L}$ sodium bicarbonate, $10 \%$ fetal bovine serum, $100 \mathrm{U} / \mathrm{ml}$ penicillin and $100 \mu \mathrm{g} /$ $\mathrm{ml}$ streptomycin at $37^{\circ} \mathrm{C}$ in a humidified atmosphere of $5 \% \mathrm{CO} 2$. Cells were fed every 2 days and sub-cultured when reaching $70-80 \%$ confluence to prevent the changes of cellular phenotype. In order to establish the hypoxic condition, $\mathrm{H} 9 \mathrm{c} 2$ cells were transferred to an airtight Plexiglas hypoxic chamber in a glucose-free medium. The hypoxic condition $(<1 \%)$ was achieved by flushing the chamber with $5 \% \mathrm{CO}_{2}$ and $95 \% \mathrm{~N}_{2}$. The hypoxia exposure was confirmed with $\mathrm{O}_{2}$ concentration monitoring and elevation of HIF- $1 \alpha$ protein abundance with Western blotting. Cell viability was examined with 
trypan blue exclusion tests. Specifically, 0.4\% trypan blue in buffered isotonic salt solution was used to stain the H9c2 cells. The blue staining cells were considered nonviable.

\section{Mitochondrial function measurements}

Measurement of cardiomyoblasts respiratory was performed using the Seahorse XF24 analyzer (Seahorse Bioscience Inc.). H9c2 cells were plated at a density of 20,000 cells/well on the XF24 plate. The cells were treated with $2.5 \mu \mathrm{g} / \mathrm{mL}$ asprosin or vehicles for $24 \mathrm{~h}$ and then exposed with or without $3 \% \mathrm{H}_{2} \mathrm{O}_{2}$ for $4 \mathrm{~h}$. Prior to the respiration assay, cells were rinsed and cultured in DMEM running medium (8.3 g/L DMEM (Sigma), 200 mM GlutaMax-1 (Invitrogen), $100 \mathrm{mM}$ sodium pyruvate (Sigma), $25 \mathrm{mM}$ D-glucose (Sigma), $63.3 \mathrm{mM} \mathrm{NaCl}$ (Sigma), and phenol red (Sigma), adjust pH to 7.4 with $\mathrm{NaOH}$ ). Oxygen consumption was measured under basal conditions, in the presence of the mitochondrial inhibitors oligomycin
$(1 \mu \mathrm{M})$ or mitochondrial uncoupler FCCP $(4 \mu \mathrm{M})$, or antimycin $\mathrm{A} /$ rotenone $(0.5 \mu \mathrm{M})$ to analyze maximal oxidative capacity and proton leak.

\section{Statistical analyses}

Continuous variables with normal distribution were described as mean \pm standard deviation and Student t-tests were used for comparison. If not normally distributed, variables were described as median with interquartile range and compared with the Mann-Whitney test. A cutoff value of elevated asprosin ( $\geq 210 \mathrm{ng} / \mathrm{mL}$ ) level was determined according to the median level of asprosin in the study cohort. The association of asprosin level and time to adverse cardiac outcomes was assessed with multivariable Cox proportional hazard analysis. Major adverse event-free survival curves were generated from the Kaplan-Meier survival analysis. Statistical analyses were performed using SPSS version 22 (IBM) and Prism

Table 1 Baseline Characteristics

\begin{tabular}{|c|c|c|c|c|}
\hline \multirow[t]{2}{*}{ Variable } & \multirow{2}{*}{$\begin{array}{l}\text { All patients } \\
(n=50)\end{array}$} & \multicolumn{2}{|l|}{ Asprosin } & \multirow{2}{*}{$\begin{array}{l}P \\
\text { value }\end{array}$} \\
\hline & & Low group $(n=25)$ & High group $(n=25)$ & \\
\hline Age, y & $55 \pm 10(35-78)$ & $55 \pm 11(35-78)$ & $54 \pm 9(36-71)$ & 0.98 \\
\hline Female gender, $n(\%)$ & $7(14.0 \%)$ & $4(16.0 \%)$ & $3(12.0 \%)$ & $>0.99$ \\
\hline Body mass index, $\mathrm{kg} / \mathrm{m}^{2}$ & $25.8 \pm 4.3$ & $25.2 \pm 4.6$ & $26.4 \pm 4.1$ & 0.44 \\
\hline Hypertension, $n$ (\%) & $14(28.0 \%)$ & $6(24.0 \%)$ & $8(32.0 \%)$ & 0.75 \\
\hline Diabetes mellitus, $n$ (\%) & $12(24.0 \%)$ & $6(24.0 \%)$ & $6(24.0 \%)$ & $>0.99$ \\
\hline Systolic blood pressure, $\mathrm{mmHg}$ & $115 \pm 21$ & $112 \pm 22$ & $118 \pm 19$ & 0.25 \\
\hline Heart rate, bpm & $80 \pm 16$ & $82 \pm 16$ & $79 \pm 18$ & 0.47 \\
\hline NYHA class III or IV, n (\%) & $15(30.0 \%)$ & $7(28.0 \%)$ & $8(32.0 \%)$ & $>0.99$ \\
\hline COPD, $n(\%)$ & $0(0.0 \%)$ & $0(0.0 \%)$ & $0(0.0 \%)$ & $>0.99$ \\
\hline Atrial fibrillation, $n(\%)$ & $17(34.0 \%)$ & $8(32.0 \%)$ & $9(36.0 \%)$ & $>0.99$ \\
\hline LV mass index, $\mathrm{g} / \mathrm{m}^{2}$ & $344.9 \pm 104.6$ & $358.0 \pm 110.7$ & $331.8 \pm 98.6$ & 0.46 \\
\hline LV end-diastolic volume index, $\mathrm{mL} / \mathrm{m}^{2}$ & $248.9 \pm 74.9$ & $248.1 \pm 81.3$ & $249.7 \pm 69.7$ & 0.99 \\
\hline LV ejection fraction, \% & $27.1 \pm 9.9$ & $26.5 \pm 10.7$ & $27.7 \pm 9.2$ & 0.63 \\
\hline Mitral E/A ratio & $1.4 \pm 0.9$ & $1.4 \pm 0.7$ & $1.4 \pm 1.1$ & 0.85 \\
\hline ACEI/ARB, $n(\%)$ & $44(88.0 \%)$ & $23(92.0 \%)$ & $21(84.0 \%)$ & 0.67 \\
\hline Beta-blockers, n (\%) & $42(84.0 \%)$ & $21(84.0 \%)$ & $21(84.0 \%)$ & $>0.99$ \\
\hline Spironolactone, $n(\%)$ & $30(60.0 \%)$ & $15(60.0 \%)$ & $15(60.0 \%)$ & $>0.99$ \\
\hline Loop diuretics, $n$ (\%) & $36(72.0 \%)$ & 19 (76.0\%) & $17(68.0 \%)$ & 0.75 \\
\hline Digoxin, $n(\%)$ & $21(42.0 \%)$ & $10(40.0 \%)$ & $11(44.0 \%)$ & $>0.99$ \\
\hline $\mathrm{BNP}, \mathrm{pg} / \mathrm{mL}$ & $1073 \pm 1199$ & $1208 \pm 1370$ & $955 \pm 1046$ & 0.74 \\
\hline $\mathrm{eGFR}, \mathrm{mL} / \mathrm{min} / 1.73 \mathrm{~m}^{2}$ & $75.4 \pm 24.5$ & $77.1 \pm 22.9$ & $73.7 \pm 26.3$ & 0.73 \\
\hline Creatinine, $\mathrm{mg} / \mathrm{dL}$ & $1.5 \pm 1.8$ & $1.7 \pm 2.4$ & $1.2 \pm 0.7$ & 0.94 \\
\hline Cholesterol, mg/dL & $156.4 \pm 35.0$ & $147.4 \pm 31.3$ & $165.5 \pm 36.8$ & 0.09 \\
\hline Sugar, mg/dL & $103.8 \pm 24.9$ & $99.6 \pm 16.7$ & $108.2 \pm 31.1$ & 0.43 \\
\hline $\mathrm{HbA1C} \%$ & $6.2 \pm 1.1$ & $6.1 \pm 1.0$ & $6.4 \pm 1.3$ & 0.54 \\
\hline
\end{tabular}

$A C E l$ angiotensin-converting-enzyme inhibitor, $A R B$ angiotensin receptor blocker, $B N P$ B-type natriuretic peptide, COPD chronic obstructive pulmonary disease, eGFR estimated glomerulus filtration rate, HbA1C glycohemoglobin, $L V$ left ventricle, NYHA New York Heart Association 
8 (GraphPad Software, LLC). P values $<0.05$ were considered statistically significant.

\section{Result}

\section{Subject characteristics}

Baseline characteristics for patients with DCM cohort are presented in Table 1. Patients with DCM had a mean age of $55 \pm 10$ years and a mean BNP concentration of $1073 \pm 1199 \mathrm{pg} / \mathrm{mL} ; 14.0 \%$ female and $30.0 \%$ were in New York Heart Association (NYHA) class III or IV. Mean asprosin level was $191.2 \mathrm{ng} / \mathrm{mL}(n=50$; $95 \%$ confidence interval $(\mathrm{CI})$ of mean $78.8-303.6 \mathrm{ng} / \mathrm{mL}$ ) in patients with DCM and $79.7 \mathrm{ng} / \mathrm{mL}$ in normal control subjects $(n=50 ; 95 \%$ CI of mean $13.9-135.5 \mathrm{ng} / \mathrm{mL}$; age, gender, and body mass index (BMI) matched). Patients with DCM have significantly higher asprosin levels when compared with the normal subjects (Fig. 1). Patients were allocated into two groups according to the median levels of asprosin. Patients with lower or higher asprosin levels exhibited no differences in age, gender, body mass index, left ventricular ejection fraction, B-type natriuretic peptide (BNP), and other clinical parameters (Table 1). The median length of follow-up was 62 months. During the follow-up period, 2 patients died, 12 readmitted with heart failure, and 2 suffered strokes.

\section{Asprosin levels and adverse cardiovascular events in DCM patients}

In our study cohort, 16 (32.0\%) patients experienced an adverse event of death, heart failure hospitalization, and strokes over the 5-year follow-up. When divided into a dichotomous variable of asprosin with a cut point of $210 \mathrm{ng} / \mathrm{mL}$, elevated asprosin was a predictor of decreased risk of 5-year adverse events (Fig. 2). Low asprosin levels showed a strong effect on adverse events in univariate Cox proportional hazard analysis with a hazard ratio of 7.94 (95\% CI $1.88-33.50 ; P=0.005)$ for the adverse long-term event outcomes (Table 2). Age, LV ejection fraction, and cholesterol were also significantly associated with future heart failure-related events (Table 2). Multivariate Cox proportional hazards analysis including the age, LV ejection fraction, and cholesterol showed that the lower asprosin level was an independent predictor of future heart failure-related events (Table 3).

The Kaplan-Meier survival analysis showed that heart failure-related events increased with the lower asprosin levels during the 60 months follow-up periods (Fig. 2).

Treatment of asprosin significantly increased cell viability under hypoxic conditions

To explore the direct function of asprosin in cardiomyocytes, we treated cardiomyoblasts $\mathrm{H} 9 \mathrm{c} 2$ cells with asprosin under hypoxia and normoxia conditions. After $6 \mathrm{~h}$ of hypoxia, we observed a marked decrease in cell viability

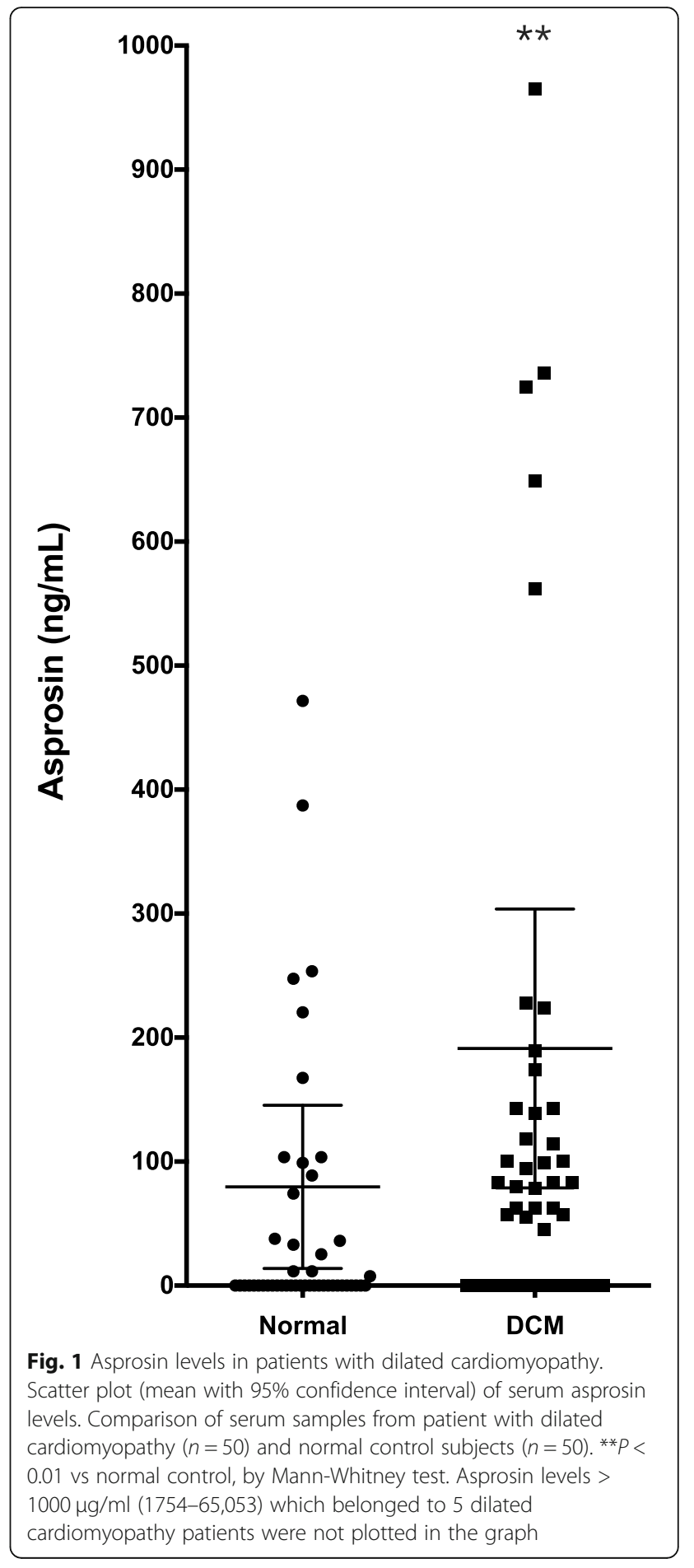

without treatment of asprosin. Treatment of asprosin significantly increased cell viability under hypoxic conditions (Fig. 3a). Furthermore, cells treated with the higher concentration $(10 \mu \mathrm{g} / \mathrm{ml})$ of asprosin exhibited enhanced cell viability when compared with lower concentration asprosin $(2.5 \mu \mathrm{g} / \mathrm{mL})$. 


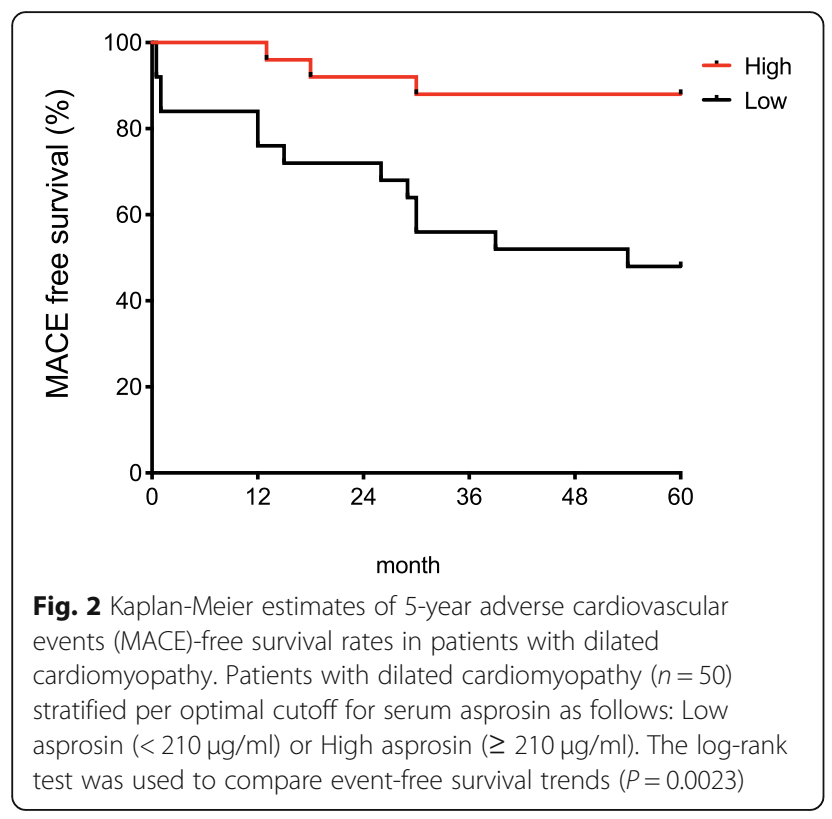

\section{Asprosin increases mitochondrial respiration and proton leak}

To further study the effects of asprosin on mitochondrial functions in cardiomyoblast, we exposed H9c2 cells with $2.5 \mu \mathrm{g} / \mathrm{mL}$ asprosin for $24 \mathrm{~h}$ and measured mitochondrial respiration with or without $\mathrm{H}_{2} \mathrm{O}_{2}$ (Fig. 3b). Asprosin

Table 2 Cox proportional hazard analyses of adverse long-term event outcomes

\begin{tabular}{|c|c|c|}
\hline \multirow[t]{2}{*}{ Variable } & \multicolumn{2}{|l|}{ Univariate analysis } \\
\hline & $\mathrm{HR}(95 \% \mathrm{Cl})$ & $P$ value \\
\hline Asprosin (< $120 \mathrm{vs} \geq 120 \mathrm{ng} / \mathrm{mL})$ & $7.94(1.88-33.50)$ & 0.005 \\
\hline Age, y & $0.93(0.87-1.00)$ & 0.04 \\
\hline Female gender, $n(\%)$ & $0.83(0.14-4.8)$ & 0.83 \\
\hline Body mass index, $\mathrm{kg} / \mathrm{m}^{2}$ & $0.09(-0.06-0.23)$ & 0.24 \\
\hline Hypertension, $n$ (\%) & $1.26(0.34-4.65)$ & 0.73 \\
\hline Diabetes mellitus, $n$ (\%) & $0.08(-1.30-1.46)$ & 0.91 \\
\hline NYHA class III or IV, n (\%) & $0.70(0.18-2.67)$ & 0.60 \\
\hline Atrial fibrillation, $n(\%)$ & $1.26(0.36-4.34)$ & 0.72 \\
\hline LV mass index, $\mathrm{g} / \mathrm{m}^{2}$ & $1.00(0.99-1.01)$ & 0.793 \\
\hline LV end-diastolic volume index, $\mathrm{mL} / \mathrm{m}^{2}$ & $1.00(0.99-1.01)$ & 0.28 \\
\hline LV ejection fraction, \% & $0.92(0.84-0.99)$ & 0.03 \\
\hline Mitral E/A ratio & $1.33(0.46-3.86)$ & 0.60 \\
\hline BNP, pg/mL & $1.00(0.99-1.00)$ & 0.20 \\
\hline $\mathrm{eGFR}, \mathrm{mL} / \mathrm{min} / 1.73 \mathrm{~m}^{2}$ & $1.00(0.98-1.03)$ & 0.79 \\
\hline Creatinine, $\mathrm{mg} / \mathrm{dL}$ & $0.66(0.25-1.76)$ & 0.40 \\
\hline Cholesterol, mg/dL & $0.97(0.95-0.99)$ & 0.007 \\
\hline Sugar, mg/dL & $0.98(0.95-1.02)$ & 0.32 \\
\hline
\end{tabular}

BNP B-type natriuretic peptide, eGFR estimated glomerulus filtration rate, LVEF left ventricle ejection fraction, NYHA New York Heart Association significantly increased the mitochondrial maximum respiration and proton leak (Fig. 3c) under the exposure of $\mathrm{H}_{2} \mathrm{O}_{2}$ in $\mathrm{H} 9 \mathrm{c} 2$ cardiomyoblasts, indicating that asprosin critically modulates mitochondrial function in $\mathrm{H} 9 \mathrm{c} 2$ cardiomyoblast cells.

\section{Discussion}

Our results demonstrated that asprosin, a novel glucogenic protein adipokine, exerts cardiac protective effects in patients with DCM. DCM patients with higher asprosin levels have less adverse cardiovascular events in 5 years. We showed that asprosin acts directly on cardiomyoblasts and enhances mitochondria respiration with proton leaks in responses to hypoxia.

Previous studies have shown that asprosin is recruited to the liver and enhances gluconeogenesis through its receptor OLFR734. Another study also shows that asprosin crosses the blood-brain barrier to activate appetite signaling. The asprosin receptor OLFR734 expresses in the olfactory epithelium, kidney, liver, muscles, adipose tissues, and testis. However, the asprosin action on cardiomyocytes is still unclear. Our data provided evidence that asprosin can act directly on cardiomyocytes and protect hypoxic injuries through mitochondrial respiration. Moreover, the asprosin abundances are affected by the dilated cardiomyopathy and associated with DCM outcomes. The OLFR734 is most abundant in the olfactory epithelium and adipose tissues [25]. It remained to be determined whether OLFR734 is the asprosin receptor in the cardiomyocytes and future study will be needed to investigate the signaling pathway of which asprosin exerts its protection from hypoxia in the heart and DCM patients.

DCM patients with higher asprosin levels in our cohort experienced fewer major cardiovascular events compared to patients with lower asprosin levels in five years follow up. Currently, the exact regulations of serum asprosin levels in humans are still unclear. Plasma asprosin exhibits an oscillatory circadian rhythm. Fasting, obesity, and insulin resistance are reported to affect asprosin levels. However, it is not known which physiological signaling or molecular mechanisms balance the homeostasis of asprosin. Our group has shown that asprosin concentrations are significantly higher in obese patients and that body weight changes after bariatric surgery are significantly associated with pre-surgical asprosin levels without associations with blood glucose or cholesterol levels [22]. These results indicated that the regulations of asprosin may not be glucose-dependent since heart failure patients and bariatric surgery outcomes both affected asprosin concentrations. Heart failure patients have multiple neurohormonal abnormalities and disturbed renin-angiotensin axis [26]. Therefore, it is possible that abnormal neurohormonal signaling may also serve as asprosin regulation in addition to the circadian rhythm or fasting status. 
Table 3 Multivariate COX proportional hazards analysis to identify predictors of heart failure-related events using forced inclusion models

\begin{tabular}{|c|c|c|c|c|c|c|}
\hline \multirow[t]{2}{*}{ Variable } & \multicolumn{2}{|l|}{ Model 1} & \multicolumn{2}{|l|}{ Model 2} & \multicolumn{2}{|l|}{ Model 3} \\
\hline & HR $(95 \% \mathrm{Cl})$ & $P$ value & HR $(95 \% \mathrm{Cl})$ & $P$ value & HR $(95 \% \mathrm{Cl})$ & $P$ value \\
\hline Asprosin, (< 120 vs $\geq 120 \mathrm{ng} / \mathrm{mL})$ & $10.53(2.18-50.81)$ & 0.003 & $8.72(1.90-39.97)$ & 0.005 & $7.13(1.51-33.69)$ & 0.013 \\
\hline Age, y & $0.92(0.85-0.99)$ & 0.026 & - & & - & \\
\hline LVEF, \% & - & & $0.91(0.84-0.99)$ & 0.036 & - & \\
\hline Cholesterol, mg/dL & - & & - & & $0.97(0.94-0.99)$ & 0.02 \\
\hline
\end{tabular}

LVEF left ventricle ejection fraction

Patients with lower or higher asprosin levels exhibited similar serum BNP concentrations. Serum BNP levels are predictors of outcomes in chronic heart failure patients [24]. However, BNP has several limitations for follow-up and diagnosis of heart failure patients [27].
BNP may be affected by renal function, body weight, and lung diseases [28]. BNP measurements alone are not sufficient to guide therapeutic decision-making in patients with heart failure [29]. The fact that patients with different asprosin levels had similar BNP concentrations in
B

A

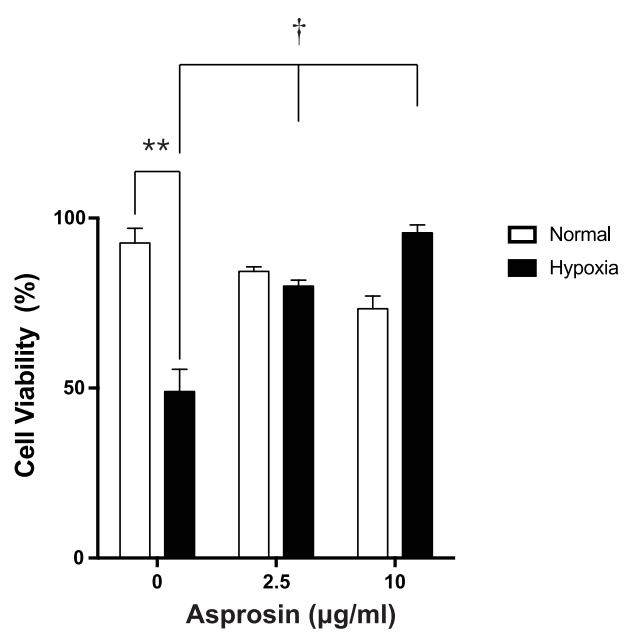

\section{Mitochondrial Respiration}

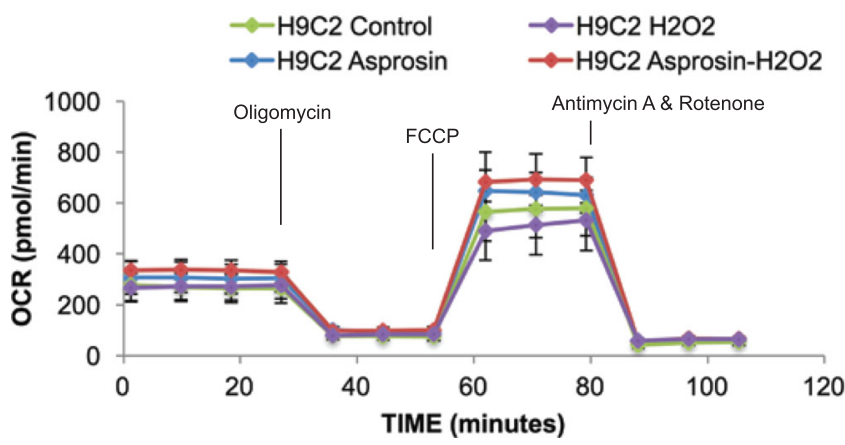

C

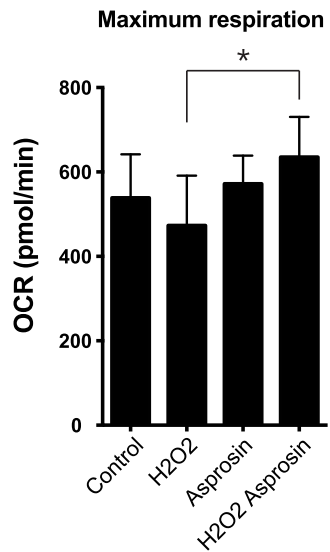

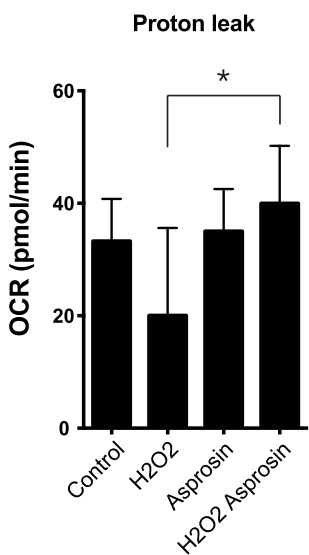

Fig. 3 a Asprosin prevents hypoxia-induced cell death. Cardiomyoblast H9c2 cells were treated with different doses of asprosin for $24 \mathrm{~h}$ and exposed to hypoxia and normoxia conditions for $6 \mathrm{~h}$. Cell viability was examined with a trypan blue exclusion test ( $n=4$ in each group). One-way analysis of variance with Greisser-Greenhouse correction and Holm-Sidak's multiple comparisons were used to calculate the changes in cell viability. ${ }^{*} P<0.01$, normoxia vs hypoxia without asprosin. $+P<0.05$, asprosin 2.5 or $10 \mu \mathrm{g} / \mathrm{ml} \mathrm{vs} 0 \mu \mathrm{g} / \mathrm{ml}$. b Asprosin increases mitochondrial respiration and proton leak. Cardiomyoblasts $\mathrm{H} 9 \mathrm{c} 2$ cells were treated with asprosin $2.5 \mu \mathrm{g} / \mathrm{ml}$ for $24 \mathrm{~h}$ and exposed to $3 \% \mathrm{H}_{2} \mathrm{O}_{2}$ for $4 \mathrm{~h}(n=4)$. Mitochondrial respiratory analysis of oxygen consumption rate. c Quantification of maximal respiration and proton leak. ${ }^{*} P<0.05, \mathrm{H}_{2} \mathrm{O}_{2}$ vs $\mathrm{H}_{2} \mathrm{O}_{2}$ with Asprosin group by Mann-Whitney test 
our cohort could indicate that the mechanisms linking cardiovascular outcomes in heart failure patients are different from BNP or asprosin.

The data in H9c2 cells showed that asprosin can protect cells from hypoxic injury. This result is consistent with that the higher asprosin concentrations are associated with better outcomes in DCM patients. However, we reasoned that there are still three questions remained to be answered in the future study. First, what is the asprosin receptor in the cardiomyocytes? The previous study has shown that OLFR734 is an asprosin receptor in the liver. Our data showed that Olfr734 mRNA in the hearts of wild-type mice is significantly lower than the mRNA in the white fat tissues $(0.13 \pm 0.03$ vs. $1 \pm 0.05$, heart vs. white fat, $P<0.05)$. Moreover, Olfr 734 knockout does not completely abolish the asprosin-stimulated effect on glucose production [21]. These observations suggest that asprosin may have other receptors in different tissues and asprosin may have functions other than glucose homeostasis in cardiomyocytes.

In the H9c2 cardiomyoblast experiments, cells treated with asprosin without hypoxia showed no significant mitochondrial function changes. Instead, cells under hypoxia injury with impaired mitochondrial respiration exhibited a significant recovery of the mitochondrial function after asprosin treatment. This data suggests that asprosin function in $\mathrm{H} 9 \mathrm{c} 2$ is hypoxia driven and may only initiate downstream cascades after cells experience hypoxia or ischemic injury. This is similar to the autophagy machinery in the cells. Hypoxia significantly induces autophagy functions in cardiomyocytes and protects cells from hypoxia while cardiomyocytes without hypoxia exhibit minimal autophagy induction [30,31]. It is not known whether asprosin will activate autophagy flux and future study will be needed.

The function of asprosin is currently unclear except for its glucogenic effects in hepatic cells [18] and orexigenic stimulation in the brain [17]. In failing heart, energy utilization and substrates expenditure are shifting from fatty acid to glucose, lactate, and ketone bodies [32]. This energy substrates switch makes energy production more efficient with $30 \%$ more ATP production by carbohydrate oxidation [33]. It is possible that asprosin also has glucogenic effects in cardiomyocytes and provides a beneficial adaptive mechanism for efficient energy production. Further studies will be needed to explore these mechanisms.

\section{Conclusions}

Our clinical studies were performed in a prospective manner with DCM patients in a single medical center. In this DCM cohort study, we did not include a control healthy group. Because our enrollment criteria included the confirmation from cardiac catheterization of normal coronary arteries, we have a smaller number of DCM patient cohort. The small cohort might limit the statistic power and the interpretation of study results. Besides, although we have avoided the possible confounding factors from heterogeneous etiologies and different phenotypes of HF patients with an enrollment of only DCM patients, the findings of our results could not directly apply to patients with other etiologies of heart failure. Future clinical studies with a larger number with a full spectrum of HF patients will be needed. Moreover, we only performed $\mathrm{H} 9 \mathrm{c} 2$ cardiomyoblasts studies in vitro to test the mechanisms of asprosin. In vivo animal studies are also required to reconfirm our findings. However, we believe that the DCM cohort provides us with clear clinical observations without the complex confounding factors in heart failure patients of many different etiologies. Moreover, our cardiomyoblast studies in vitro provide direct evidence that asprosin exerts significant effects in the cardiovascular field.

\section{Acknowledgments}

The authors thank Mei-Hsiu Lin, Hui-Ting Su, Tsu-Hui Yeh, Yo-Yu Ying, ChihJung Chang, Ko-Chiang Chou, and Yu-Chun Chuang for technical assistance.

\section{Authors' contributions}

M.S.W. conceived, designed, and executed the project and experiments. M.L.T., C.C.C., J.K.Y., M.Y.H., K.C.H., I.C.H., C.Y.W., recruited the patients, analyzed the data, provided project concepts, and wrote the article. C.Y.W. supervised the project and wrote the article. The authors take responsibility for all aspects of the reliability and freedom from bias of the data presented and their discussed interpretation. The author(s) read and approved the final manuscript.

\section{Funding}

C.Y.W. received support from the National Health Research Institute (NHRIEX106-10617SI), National Science Council (105-2628-B-182-009-MY4, 1092314-B-182-070-MY3), and Chang Gung Memorial Hospital (CMRPG3H0133, CMRPG3H0843, CMRPG3I0322, and CORPG3K0011). M.S.W. received support from National Science Council (108-2314-B-182A-134 -MY3). I.C.H. received support from National Science Council (108-2314-B-182A-135). J.K.Y. received support from Chang Gung Memorial Hospital (CMRPG3I0061).

\section{Availability of data and materials}

The data used to support the findings of this study are available from the corresponding author upon request.

\section{Ethics approval and consent to participate}

The study protocol was approved by the institutional review board of the Chang Gung Memorial Hospital. All patients provided written informed consent

\section{Consent for publication \\ Not applicable.}

\section{Competing interests}

The authors declare that they have no competing interests, and all authors should confirm its accuracy.

\section{Author details}

'Department of Cardiology, Chang Gung Memorial Hospital, and Chang Gung University College of Medicine, 5 Fu-Hsing Street, Taoyuan 333, Taiwan. ${ }^{2}$ Institute of Cellular and System Medicine, National Health Research Institutes, Zhunan 350, Taiwan. 
Received: 14 July 2020 Accepted: 23 August 2020

Published online: 07 September 2020

\section{References}

1. Ambrosy AP, Fonarow GC, Butler J, Chioncel O, Greene SJ, Vaduganathan M, et al. The global health and economic burden of hospitalizations for heart failure: lessons learned from hospitalized heart failure registries. J Am Coll Cardiol. 2014;63:1123-33

2. Blecker S, Paul M, Taksler G, Ogedegbe G, Katz S. Heart failure-associated hospitalizations in the United States. J Am Coll Cardiol. 2013;61:1259-67.

3. Çiçekçioğlu H, Çetin M, Duyuler PT, Özbek K. Utility of ACUTE-HF score in patients with acute heart failure. Int J Cardiol. 2020;300:208.

4. Greene SJ, Fonarow GC, Vaduganathan M, Khan SS, Butler J, Gheorghiade M. The vulnerable phase after hospitalization for heart failure. Nat Rev Cardiol. 2015;12:220-9.

5. Wilcox JE, Fonarow GC, Ardehali H, Bonow RO, Butler J, Sauer AJ, et al. "Targeting the heart" in heart failure: myocardial recovery in heart failure with reduced ejection fraction. JACC. 2015;3:661-9.

6. Koitabashi N, Kass DA. Reverse remodeling in heart failure-mechanisms and therapeutic opportunities. Nat Rev Cardiol. 2012:9:147-57.

7. Doenst T, Nguyen TD, Abel ED. Cardiac metabolism in heart failure: implications beyond ATP production. Circ Res. 2013;113:709-24.

8. Fukushima A, Milner K, Gupta A, Lopaschuk GD. Myocardial energy substrate metabolism in heart failure : from pathways to therapeutic targets. Curr Pharm Des. 2015;21:3654-64.

9. Hardy CJ, Weiss RG, Bottomley PA, Gerstenblith G. Altered myocardial highenergy phosphate metabolites in patients with dilated cardiomyopathy. Am Heart J. 1991:122(3 Pt 1):795-801.

10. Conway MA, Allis J, Ouwerkerk R, Niioka T, Rajagopalan B, Radda GK. Detection of low phosphocreatine to ATP ratio in failing hypertrophied human myocardium by 31P magnetic resonance spectroscopy. Lancet. 1991;338:973-6.

11. Lai L, Leone TC, Keller MP, Martin OJ, Broman AT, Nigro J, et al. Energy metabolic reprogramming in the hypertrophied and early stage failing heart: a multisystems approach. Circ Heart Fail. 2014;7:1022-31.

12. Chen Q, Younus M, Thompson J, Hu Y, Hollander JM, Lesnefsky EJ. Intermediary metabolism and fatty acid oxidation: novel targets of electron transport chain-driven injury during ischemia and reperfusion. Am J Physiol Heart Circ Physiol. 2018:314:H787-95.

13. Hafstad AD, Nabeebaccus AA, Shah AM. Novel aspects of ROS signalling in heart failure. Basic Res Cardiol. 2013:108:359.

14. Sarma S, Ardehali H, Gheorghiade M. Enhancing the metabolic substrate: PPAR-alpha agonists in heart failure. Heart Fail Rev. 2012;17:35-43.

15. Saotome M, Ikoma T, Hasan P, Maekawa Y. Cardiac insulin resistance in heart failure: the role of mitochondrial dynamics. Int J Mol Sci. 2019;20(14): 3552

16. Borlak J, Thum T. Hallmarks of ion channel gene expression in end-stage heart failure. FASEB J. 2003;17:1592-608.

17. Duerrschmid C, He Y, Wang C, Li C, Bournat JC, Romere C, et al. Asprosin is a centrally acting orexigenic hormone. Nat Med. 2017;23:1444-53.

18. Romere C, Duerrschmid C, Bournat J, Constable P, Jain M, Xia F, et al. Asprosin, a fasting-induced Glucogenic protein hormone. Cell. 2016;165: 566-79

19. Greenhill C. Liver: Asprosin - new hormone involved in hepatic glucose release. Nat Rev Endocrinol. 2016;12:312.

20. Jung TW, Kim H-C, Kim HU, Park T, Park J, Kim U, et al. Asprosin attenuates insulin signaling pathway through PKC $\delta$-activated ER stress and inflammation in skeletal muscle. J Cell Physiol. 2019;234:20888-99.

21. Li E, Shan H, Chen L, Long A, Zhang Y, Liu Y, et al. OLFR734 Mediates Glucose Metabolism as a Receptor of Asprosin. Cell Metab. 2019;30:319-28 e8.

22. Wang C-Y, Lin T-A, Liu K-H, Liao C-H, Liu Y-Y, Wu VC-C, et al. Serum asprosin levels and bariatric surgery outcomes in obese adults. Int J Obes. 2019;43: 1019-25.

23. Yeh J-K, Liu W-H, Wang C-Y, Lu J-J, Chen C-H, Wu-Chou Y-H, et al. Targeted next generation sequencing for genetic mutations of dilated cardiomyopathy. Acta Cardiol Sin. 2019:35:571-84.

24. van der Meer P, Gaggin HK, Dec GW. ACC/AHA versus ESC guidelines on heart failure: JACC guideline comparison. J Am Coll Cardiol. 2019;73:275668
25. Wei F, Long A, Wang Y. The Asprosin-OLFR734 hormonal signaling axis modulates male fertility. Cell Discov. 2019:5:55.

26. McCullough M, Caraballo C, Ravindra NG, Miller PE, Mezzacappa C, Levin A, et al. Neurohormonal blockade and clinical outcomes in patients with heart failure supported by left ventricular assist devices. JAMA Cardiol. 2019;5(2): $175-82$.

27. Li X, Chen C, Gan F, Wang Y, Ding L, Hua W. Plasma NT pro-BNP, hs-CRP and big-ET levels at admission as prognostic markers of survival in hospitalized patients with dilated cardiomyopathy: a single-center cohort study. BMC Cardiovasc Disord. 2014;14:67.

28. Silver MA, Maisel A, Yancy CW, McCullough PA, Burnett JC Jr, Francis GS, et al. BNP consensus panel 2004: a clinical approach for the diagnostic, prognostic, screening, treatment monitoring, and therapeutic roles of natriuretic peptides in cardiovascular diseases. Congest Heart Fail. 2004;10: $1-30$.

29. Januzzi JL, Troughton R. Are serial BNP measurements useful in heart failure management? Serial natriuretic peptide measurements are useful in heart failure management. Circulation. 2013;127:500-7 discussion 508

30. Chang J-C, Hu W-F, Lee W-S, Lin J-H, Ting P-C, Chang H-R, et al. Intermittent hypoxia induces autophagy to protect Cardiomyocytes from endoplasmic reticulum stress and apoptosis. Front Physiol. 2019;10:995.

31. Bellot G, Garcia-Medina R, Gounon P, Chiche J, Roux D, Pouysségur J, et al. Hypoxia-induced autophagy is mediated through hypoxia-inducible factor induction of BNIP3 and BNIP3L via their BH3 domains. Mol Cell Biol. 2009; 29:2570-81

32. Turer A, Altamirano F, Schiattarella GG, May H, Gillette TG, Malloy CR, et al. Remodeling of substrate consumption in the murine STAC model of heart failure. J Mol Cell Cardiol. 2019;134:144-53.

33. de Las Fuentes L, Herrero P, Peterson LR, Kelly DP, Gropler RJ, Dávila-Román VG. Myocardial fatty acid metabolism: independent predictor of left ventricular mass in hypertensive heart disease. Hypertension. 2003;41:83-7.

\section{Publisher's Note}

Springer Nature remains neutral with regard to jurisdictional claims in published maps and institutional affiliations.
Ready to submit your research? Choose BMC and benefit from:

- fast, convenient online submission

- thorough peer review by experienced researchers in your field

- rapid publication on acceptance

- support for research data, including large and complex data types

- gold Open Access which fosters wider collaboration and increased citations

- maximum visibility for your research: over $100 \mathrm{M}$ website views per year

At $\mathrm{BMC}$, research is always in progress.

Learn more biomedcentral.com/submissions 